\title{
Stress intensity factor solutions for CTS mixed mode specimen
}

\author{
F.V. Antunes, R. Branco, J.A.M. Ferreira, L.P. Borrego \\ University of Coimbra, Portugal \\ fernando.ventura@dem.uc.pt, http:/ /orcid.org/0000-0002-0336-4729 \\ ricardo.branco@dem.uc.pt, bttp://orcid.org/0000-0001-2345-6789 \\ martins.ferreira@dem.uc.pt,borrego@isec.pt
}

\begin{abstract}
The Compact Tension Shear (CTS) specimen is used to study fracture and fatigue under mixed mode I/II loading conditions. The K solution available in literature was developed for fracture studies and does not consider the effect of crack deflection. The aim of present work is to develop $K_{I}$ and $K_{I I}$ empirical solutions for cracks with different crack lengths, loading angles and crack orientations. A total number of 1120 cracked geometries were studied numerically with the finite element method and analytical solutions were fitted to the numerical predictions. An average difference of $0.53 \%$ was found between numerical predictions and the analytical solution proposed for $\mathrm{K}_{\mathrm{I}}$. For $\mathrm{K}_{\mathrm{II}}$ the difference is higher, but the equivalent stress intensity factor showed a difference of only $1 \%$ because $K_{I I}$ is lower than $K_{I}$. Experimental work was developed to study fatigue crack growth in CTS specimens. The cracks always adopted a direction approximately normal to loading direction, i.e., tend to propagate under mode I.
\end{abstract}

KEYWORDS. CTS specimen; Stress intensity factor solution; Mixed mode

\section{OPEN ACCESS}

Citation: Antunes, F. V., Branco, R., Ferreira, J.A.M., Borrego, L.P., Stress Intensity Factor Solutions for CTS Mixed Mode Specimen, Frattura ed Integrità Strutturale, 48 (2019) 676-692.

Received: 06.10 .2018

Accepted: 28.11 .2018

Published: 01.01 .2019

Copyright: (C) 2019 This is an open access article under the terms of the CC-BY 4.0, which permits unrestricted use, distribution, and reproduction in any medium, provided the original author and source are credited.

\section{INTRODUCTION}

$\mathrm{T}$ he majority of studies on fracture toughness and fatigue crack propagation are performed for mode I loading. However, there are situations where the cracks are not normal to maximum principal stress direction. Furthermore, at microscale level, depending on microstructural details, deviations in crack direction may occur even under mode I loading. Macroscopic crack deflection occurs due to asymmetry in stresses near the crack tip, resulting from multi-axial far field loading or from non-uniformity in mechanical properties near the crack tip.

Since mixed mode loading tests are not standardized, several specimens have been developed. A geometry widely used to study mixed mode I/II loading, named compact tension shear (CTS), was developed by Richard [1]. It is a rectangular specimen with through crack and three holes for fixing on each side. This geometry was used to study fracture toughness and fatigue crack growth of metallic materials [2,3], laminated composites [4], adhesive joints [5,6], Ce-TZP/alumina composite [7], etc. Banks-Sills et al. [8] modified the CTS specimen considering a lower width at the center of the 
specimen, where the crack is positioned. Recently, Lo et al. [9] suggested a third version similar to the original one but with a different positioning of the holes. Other geometries have been used to study mixed mode I/II loading namely the compact mixed-mode specimen, CMM [10], the asymmetric three-point single edge notch bend specimen, aSENB3, and the asymmetric four-point single edge notch bend specimen, aSENB4 [11]. For mixed mode I/III loading a modified compact tension specimen (MCT) was developed [12]. For materials submitted to compressive loads (like glass) alternative specimens were developed, namely the cracked brazilian disc specimen, CBD [13] and the double clivage drilled compression, DCDC [14].

Richard et al. [15] obtained $\mathrm{K}_{\mathrm{I}}$ and $\mathrm{K}_{\mathrm{II}}$ solutions for the original CTS geometry, presented in Appendix A, considering that the crack was plane and normal to lateral faces. These solutions are adequate for fracture studies, since pre-cracks are obtained under mode I loading therefore do not suffer crack deflection. However, cracks submitted to mixed mode fatigue loading change orientation searching mode I loading and Richard's solutions can be inadequate since they have been developed for straight cracks.

Therefore, the objective of the present work is the development of $K_{I}, K_{I I}$ solutions for the CTS mixed mode specimen which include the influences of crack length, loading angle and crack orientation. This way, literature solution is extended for fatigue studies under mixed mode loading. Several crack geometries were studied numerically by the finite element method in order to obtain $\mathrm{K}_{\mathrm{I}}, \mathrm{K}_{\mathrm{II}}$, and analytical solutions were fitted to the numerical predictions.

\section{Numerical Procedure}

$\mathrm{F}$ ig. 1 presents the geometry of the Compact Tension Shear (CTS) specimen studied here. It has a width of $90 \mathrm{~mm}$, a total height of $148 \mathrm{~mm}$, and a thickness of $3 \mathrm{~mm}$, and is identical to Richard's specimen [1], except in the thickness. The thickness affects the shape of crack front, but a reduced effect on crack orientation may be expected. A pre-crack submitted to cyclic loading changes its direction approaching direction normal to remote loading, i.e., approaching mode I. A main geometrical parameter is therefore the slope at the crack tip, $\beta$. The specimens used in the experimental work had an initial notch depth $\mathrm{a}_{0}=42.5 \mathrm{~mm}$, however cracks with less extent were studied numerically to enable the reduction of initial notch depth in posterior studies.

This specimen geometry was tested with the loading device shown in Fig. 2. This apparatus was based on the mixed-mode fracture testing technique originally developed by Richard [16]. The loading device allows to apply pure mode-I, pure mode-II, as well as mixed-mode loading to the CTS specimen just by changing the loading angle $\alpha$ between the longitudinal axis of the specimen and the load direction applied by a uniaxial tension testing machine.

Fig. 3 defines load direction, $\alpha$, and boundary conditions. The specimen has circular holes but the loading device has elongated holes. The holes 1, 3, 4, 6 are elongated in the direction parallel to the crack so that forces $\mathrm{F}_{1}, \mathrm{~F}_{3}, \mathrm{~F}_{4}$ and $\mathrm{F}_{6}$ are normal to the crack plane. On the other hand, holes 2 and 5 are elongated perpendicular to the crack so that only the forces $F_{2}$ and $F_{5}$ parallel to the crack can be transmitted from the load device to the specimen. The uniaxial load $F$ is related with punctual loads according [16]:

$$
\begin{aligned}
& \mathrm{F}_{1}=\mathrm{F}_{6}=\mathrm{F} \cdot\left(\frac{1}{2} \cos \alpha+\frac{\mathrm{c}}{\mathrm{b}} \sin \alpha\right) \\
& \mathrm{F}_{2}=\mathrm{F}_{5}=\mathrm{F} \cdot \sin \alpha \\
& \mathrm{F}_{3}=\mathrm{F}_{4}=\mathrm{F} \cdot\left(\frac{1}{2} \cos \alpha-\frac{\mathrm{c}}{\mathrm{b}} \sin \alpha\right)
\end{aligned}
$$

The material studied was the AlMgSi1 (6082) aluminium alloy with a T6 heat treatment. The T6 heat treatment corresponds to a conversion of heat-treatable material to the age-hardened condition by solution treatment, quenching and artificial age-hardening. The chemical composition and the mechanical properties of the alloy are shown in Tabs. 1 and 2 , respectively.

\begin{tabular}{ccccccccc}
\hline $\mathrm{Si}$ & $\mathrm{Mg}$ & $\mathrm{Mn}$ & $\mathrm{Fe}$ & $\mathrm{Cr}$ & $\mathrm{Cu}$ & $\mathrm{Zn}$ & $\mathrm{Ti}$ & Other \\
1.05 & 0.80 & 0.68 & 0.26 & 0.01 & 0.04 & 0.02 & 0.01 & 0.05 \\
\hline
\end{tabular}

Table 1: Chemical composition of 6082-T6 aluminium alloy (wt. \%). 


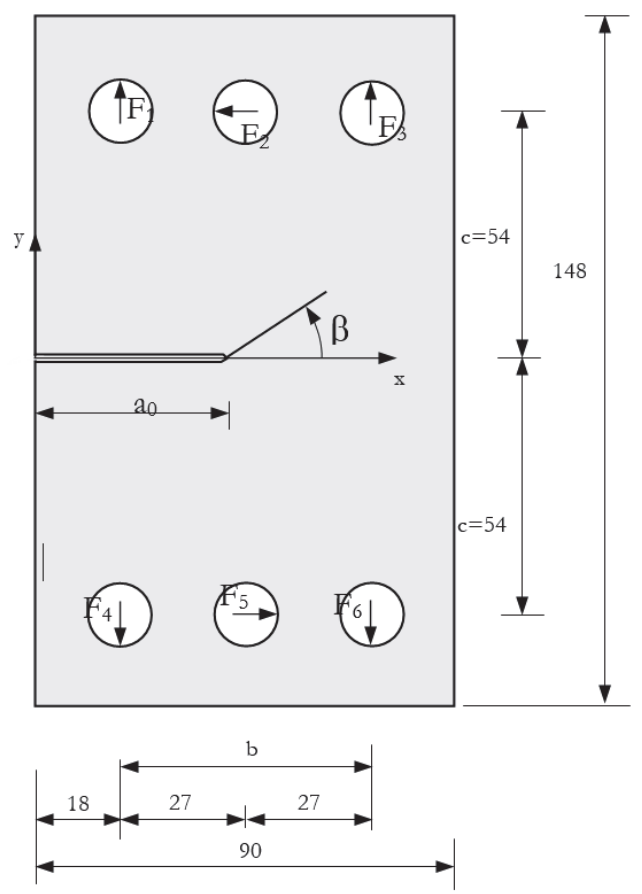

Figure 1: Geometry and loading of CTS specimen.

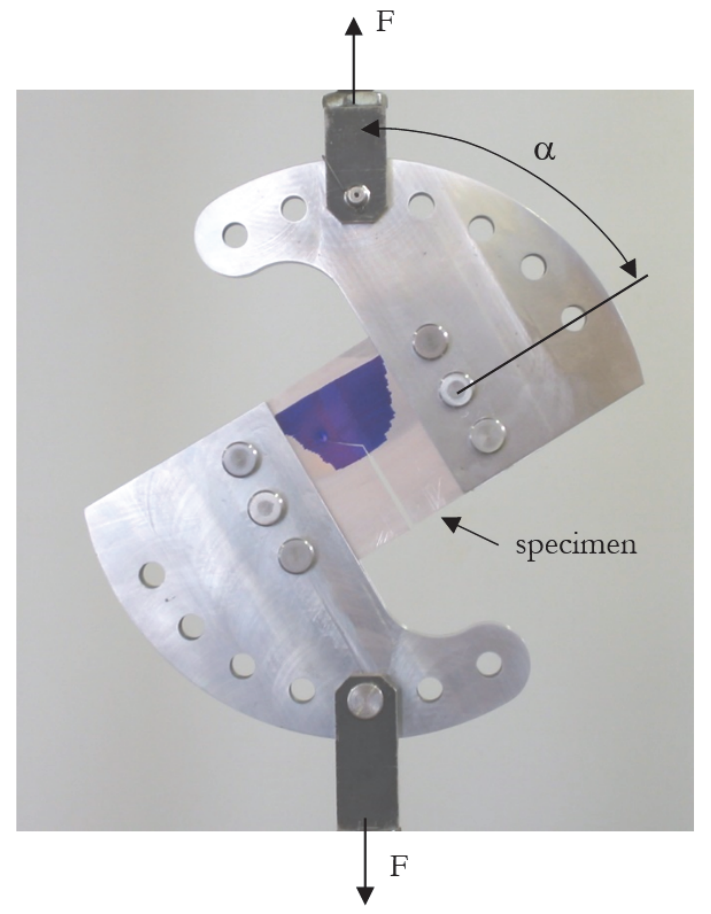

Figure 2: Mixed-mode loading device $\left(\alpha=60^{\circ}\right)$.

A 2D analysis was developed numerically, assuming a plane strain state. Due to lack of symmetry in terms of loading and geometry of the crack, the whole specimen was analyzed. The boundary conditions considered are presented in Fig. 3, and intend to avoid rigid body movement without affecting the global rigidity of the specimen. The material was assumed to be homogeneous, isotropic with linear elastic behaviour. The elastic properties considered were $\mathrm{E}=74000 \mathrm{MPa}$ and $v=0.33$.

The physical model was analyzed using CosmosM 2.0, a commercial finite element package. Quadrilateral isoparametric elements with 8 nodes were considered. Singular elements with nodes at quarter-point positions were considered at the crack tip. Fig. 4 presents the finite element mesh considered for $x=52.5 \mathrm{~mm}, \mathrm{y}=0$ and $\beta=20^{\circ}$. The crack kinks at $\mathrm{x}=0$, however the crack slope relevant is that at the crack tip. Location of (x,y) Cartesian coordinates and slope at the crack tip $(\beta)$ are defined in Fig. 1. The meshes had 4804 elements and 15075 nodes. The geometry of crack remote from its tip does not influence $\mathrm{K}$ values.

\begin{tabular}{lc}
\hline \multicolumn{1}{c}{$\mathrm{Si}$} & Other \\
Tensile strength, $\sigma_{U \mathrm{UTS}}[\mathrm{MPa}]$ & $300 \pm 2.5$ \\
Yield strength, $\sigma_{\mathrm{YS}}[\mathrm{MPa}]$ & $245 \pm 2.7$ \\
Elongation, $\varepsilon_{\mathrm{r}}[\%]$ & 9 \\
Cyclic hardening exponent, $\mathrm{n}^{\prime}$ & 0.064 \\
Cyclic hardening coefficient, $\mathrm{K}^{\prime}[\mathrm{MPa}]$ & 443 \\
Fatigue strength exponent, b & -0.0695 \\
Fatigue strength coefficient, $\sigma_{\mathrm{f}}^{\prime}[\mathrm{MPa}]$ & 485 \\
Fatigue ductility exponent, c & -0.827 \\
Fatigue ductility coefficient, $\varepsilon_{\mathrm{f}}^{\prime}$ & 0.773 \\
\hline
\end{tabular}

Table 2: Mechanical properties of the 6082-T6 aluminium alloy [3].

The accuracy of numerical predictions was checked by comparing with literature solution presented in Appendix A for $\beta=0^{\circ}$ [16]. Differences lower than $2 \%$ were obtained for $K_{I}$ and $K_{I I}$ which is a good indication for the accuracy of the results. A numerical analysis was also done using MARC-Mentat 2000 considering square elements with $8 \times 8 \mu \mathrm{m}$ at the crack tip for a total number of 6700 elements and 20727 nodes. Mode I predictions were similar to CosmosM results. 


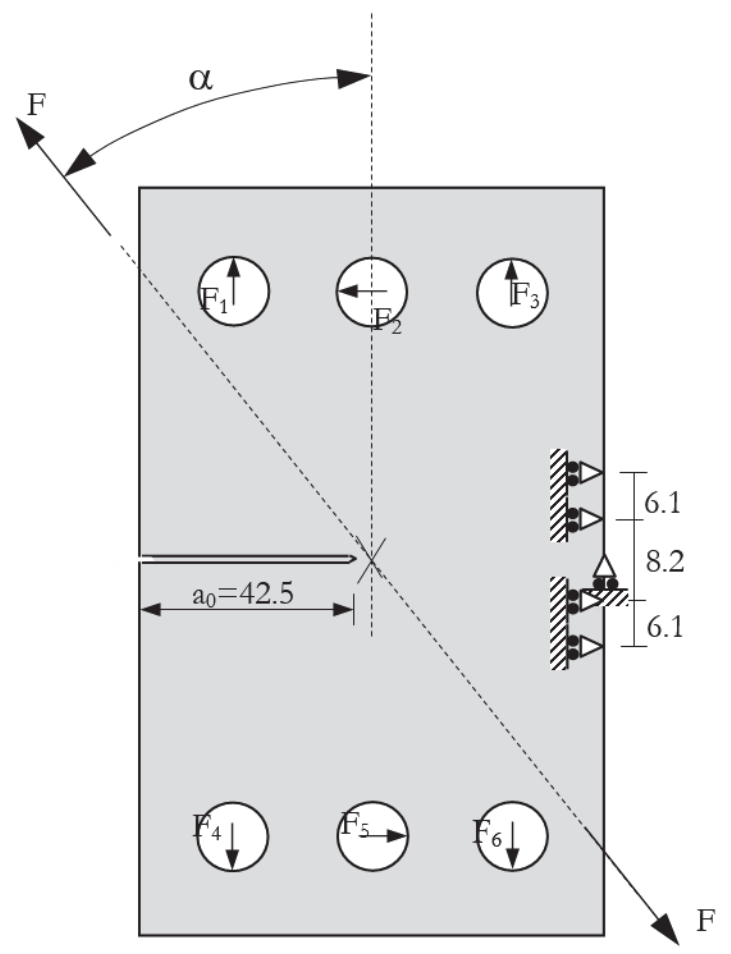

Figure 3: Loading and boundary conditions of the CTS specimen.

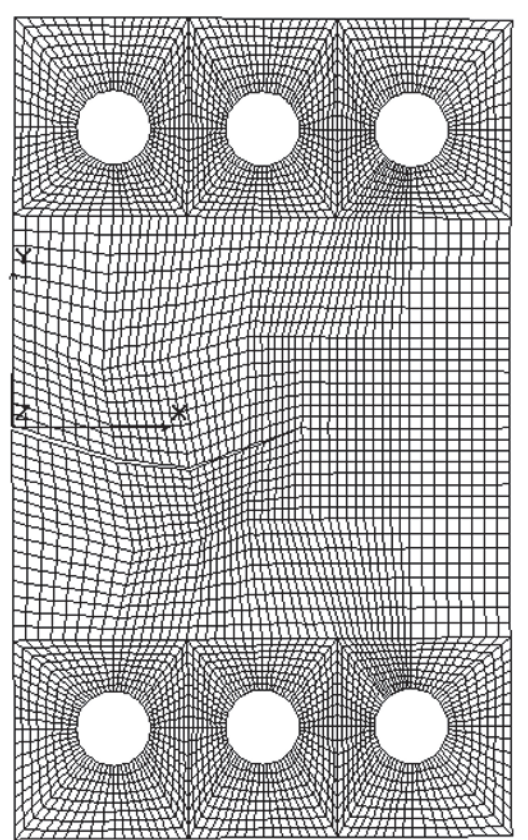

Figure 4: Typical finite element mesh $\left(x=52.5 ; y=0 ; \beta=20^{\circ}\right)$.

\section{Presentation AND ANALYSIS OF NUMERICAL RESUltS}

he stress intensity factors $\left(\mathrm{K}_{\mathrm{I}}, \mathrm{K}_{\mathrm{II}}\right)$ depend on:

- the geometry of the specimen, characterized by its width, W;

- the geometry of the crack, characterized by the Cartesian coordinates of its tip ( $\mathrm{x}, \mathrm{yP}$ ) and by the slope at its tip $(\beta$ in Fig. 1);

- the magnitude and direction of the load, which can be characterized by $\sigma(=\mathrm{F} /(\mathrm{w} \times \mathrm{t})$, being $\mathrm{t}$ the thickness of the specimen) and $\alpha$ (Figs. 2 and 3), respectively:

$$
K_{I}, K_{I I}=\tilde{f}\left(\sigma, W, x_{P}, y_{P}, \alpha, \beta\right)
$$

The number of independent variables can be reduced using Buckingham's theorem of non dimensional analysis [17]. Considering $\sigma$ and $\mathrm{x}$ the primary variables, the following non-dimensional relations can be obtained:

$$
\begin{aligned}
& \mathrm{Y}_{\mathrm{I}}=\frac{\mathrm{K}_{\mathrm{I}}}{\sigma \cdot \sqrt{\pi \cdot \mathrm{x}}}=\tilde{\mathrm{f}}\left(\frac{\mathrm{x}}{\mathrm{W}}, \frac{\mathrm{y}}{\mathrm{W}}, \alpha-\beta, \beta\right) \\
& \mathrm{Y}_{\mathrm{II}}=\frac{\mathrm{K}_{\mathrm{II}}}{\sigma \cdot \sqrt{\pi \cdot \mathrm{x}}}=\tilde{\mathrm{f}}\left(\frac{\mathrm{x}}{\mathrm{W}}, \frac{\mathrm{y}}{\mathrm{W}}, \alpha-\beta, \beta\right)
\end{aligned}
$$

This approach reduces the number of independent variables, and $\mathrm{Y}_{\mathrm{I}}, \mathrm{Y}_{\mathrm{II}}$ are independent of unit system and can be used to specimens similar to present one, which is interesting since CTS specimen is not a standard geometry.

To obtain relations 3 and 4 several numerical analyses were performed in order to obtain $Y_{I}$ and $Y_{I I}$ for the different independent parameters. The values considered for x were 32.5, 37.5, 42.5, 47.5, 52.5, 57.5, 62.5 and $67.5 \mathrm{~mm}$, and for $\mathrm{y}$ were $0,5,10$ and $15 \mathrm{~mm}$. Only zero and positive values were considered for y because crack deflects always towards mode 
I loading. Different values of $\alpha$ and $\beta$ were considered for each of these 24 crack tip positions. The values considered for $\alpha$ were $0,10,20,30,40,50$ and $60^{\circ}$, while for $\beta$ were $0,10,20,30,40$, therefore a total number of 1120 numerical analysis were performed. $J$ integral values $\mathrm{J}_{\mathrm{I}}$ and $\mathrm{J}_{\mathrm{II}}$ ) were obtained for each analysis, from which $\mathrm{K}_{\mathrm{I}}$ and $\mathrm{K}_{\mathrm{II}}$ were calculated according:

$$
\mathrm{K}_{\mathrm{I}}=\sqrt{\frac{\mathrm{E} \cdot \mathrm{J}_{\mathrm{I}}}{1-v^{2}}} \quad \mathrm{~K}_{\mathrm{II}}=\sqrt{\frac{\mathrm{E} \cdot \mathrm{J}_{\mathrm{II}}}{1-v^{2}}}
$$

Finally, $Y_{I}$ and $Y_{I I}$ were obtained using relations 3 and 4. Tabs. B1 and B2 in Appendix B present results obtained for $Y_{I}$ and $Y_{I I}$, respectively, with CosmosM software.

Typical variations of geometric factor, $\mathrm{Y}_{\mathrm{I}}$, with $(\alpha-\beta), \beta, \mathrm{y}$ and $(\mathrm{W} /(\mathrm{W}-\mathrm{x}))^{1.5}$ can be seen in Figs. $5 \mathrm{a}, 5 \mathrm{~b}, 5 \mathrm{c}$ and $5 \mathrm{~d}$, respectively. Maximum values can be observed in Fig. 5 a for $(\alpha-\beta)$ close to zero, which could be expected as zero correspond to pure mode I loading. However, the maximum value is not always zero, which indicates that there are others aspects influencing the geometric factors apart from loading direction. A good fitting is obtained with second order polynomial or sinusoidal function. A second order polynomial also fits well to results in Fig. 5b. It can be seen that the increase of slope at crack tip $(\beta)$, keeping all the others parameters fixed, reduces $\mathrm{Y}_{\mathrm{I}}$. The typical results presented in Fig. $5 \mathrm{c}$ show a linear variation with y. Finally, Fig. $5 \mathrm{~d}$ shows a linear variation of $\mathrm{Y}_{\mathrm{I}}$ with $(\mathrm{W} /(\mathrm{W}-\mathrm{x}))^{1.5}$. This variation is related with the asymmetric geometry of the specimen, which imposes flexure to non-cracked section. The increase of crack length decreases the height of rectangular non-cracked section, and increases flexure moment. The comparison between Figs. 5 indicates that highest variation of $Y_{I}$ occurs with $\mathrm{x}$ and then with $(\alpha-\beta)$.
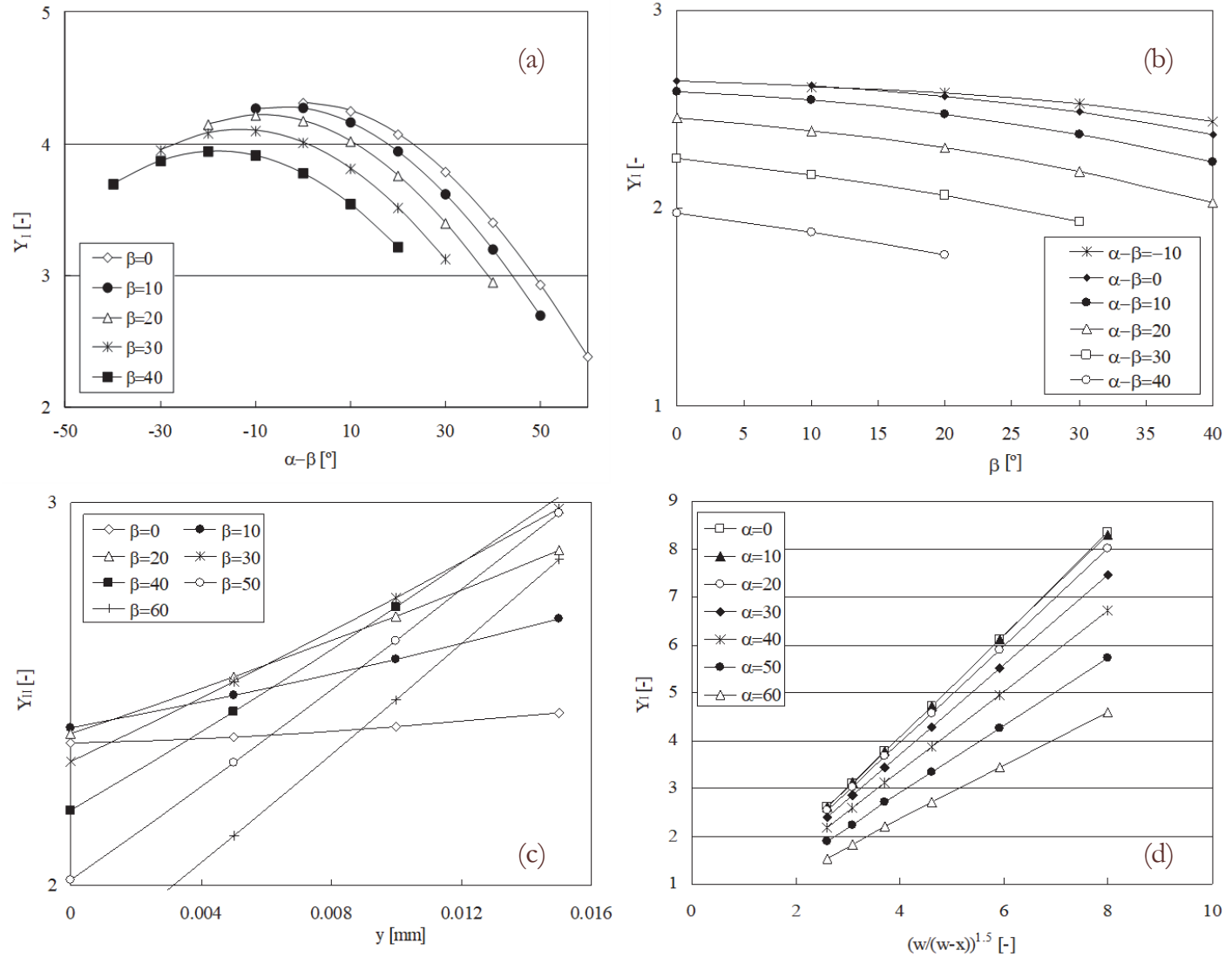

Figure 5: Variation of $Y_{I}$ with (a) $(\alpha-\beta)$ (for $x=52.5 \mathrm{~mm}$; $y=0$ ). (b) crack tip slope, $(\beta)$ (for $x=52.5 \mathrm{~mm}$; $y=0$ ). (c) y (for $x=37.5 \mathrm{~mm}$; $\left.\beta=0^{\circ}\right)$. (d) $(\mathrm{W} /(\mathrm{W}-\mathrm{x}))^{1} \cdot 5\left(\right.$ for $\left.\mathrm{y}=0 ; \beta=10^{\circ}\right)$.

A numerical solution with 39 constants was fitted to the numerical results presented in Tab. 4 (Appendix B) and illustrated in Figs. 5:

$$
\mathrm{Y}_{\mathrm{I}}=\mathrm{m} \cdot(\mathrm{W} /(\mathrm{W}-\mathrm{x}))^{1.5}+\mathrm{b}
$$




$$
\begin{aligned}
& m=a_{m} \cdot(\alpha-\beta)^{2}+b_{m} \cdot(\alpha-\beta)+c_{m} \\
& \mathrm{a}_{\mathrm{m}}=\mathrm{m}_{\mathrm{am}} \cdot(\mathrm{y} / \mathrm{W})+\mathrm{b}_{\mathrm{am}} \\
& \mathrm{m}_{\mathrm{am}}=8.4471 \times 10^{-9} \cdot \beta^{2}-4.6826 \times 10^{-8} \cdot \beta-1.5894 \times 10^{-4} \\
& b_{a m}=1.2076 \times 10^{-8} \beta^{2}-1.9219 \times 10^{-7} . \beta-1.3955 \times 10^{-4} \\
& \mathrm{~b}_{\mathrm{m}}=\mathrm{m}_{\mathrm{bm}} \cdot(\mathrm{y} / \mathrm{W})+\mathrm{b}_{\mathrm{bm}} \\
& m_{b m}=-2.3457 \times 10^{-6} \beta^{2}-2.9335 \times 10^{-4} \beta+4.1625 \times 10^{-2} \\
& b_{b m}=9.6990 \times 10^{-7} \beta^{2}-2.4575 \times 10^{-4} \beta-2.8677 \times 10^{-4} \\
& \mathrm{c}_{\mathrm{m}}=\mathrm{m}_{\mathrm{cm}} \cdot(\mathrm{y} / \mathrm{W})+\mathrm{b}_{\mathrm{cm}} \\
& \mathrm{m}_{\mathrm{cm}}=-2.7508 \times 10^{-4} \beta^{2}+4.3628 \times 10^{-2} \beta-3.7856 \times 10^{-2} \\
& b_{\mathrm{cm}}=-1.5507 \times 10^{-4} \beta^{2}-9.5592 \times 10^{-4} \beta+1.0744 \\
& b=a_{b} \cdot(\alpha-\beta)^{2}+b_{b} \cdot(\alpha-\beta)+c_{b} \\
& a_{b}=a_{a b} \cdot \beta^{2}+b_{a b} \cdot \beta+c_{a b} \\
& \mathrm{a}_{\mathrm{ab}}=4.9864 \times 10^{-8} \cdot(\mathrm{y} / \mathrm{W})+1.4723 \times 10^{-8} \\
& \mathrm{~b}_{\mathrm{ab}}=-2.9412 \times 10^{-6} \cdot(\mathrm{y} / \mathrm{W})-1.9886 \times 10^{-6} \\
& c_{a b}=-2.6726 \times 10^{-4} \cdot(y / W)+3.0499 \times 10^{-5} \\
& b_{b}=a_{b b} \cdot \beta^{2+} b_{b b} \cdot \beta+c_{b b} \\
& \mathrm{a}_{\mathrm{bb}}=-4.3391 \times 10^{-5} \cdot(\mathrm{y} / \mathrm{W})^{2}+2.1155 \times 10^{-6} \cdot(\mathrm{y} / \mathrm{W})-5.3868 \times 10^{-6} \\
& \mathrm{~b}_{\mathrm{bb}}=2.1858 \times 10^{-3} \cdot(\mathrm{y} / \mathrm{W})^{2}-9.6565 \times 10^{-4} \cdot(\mathrm{y} / \mathrm{W})+5.8686 \times 10^{-4} \\
& \mathrm{c}_{\mathrm{bb}}=5.7786 \times 10^{-2} \cdot(\mathrm{y} / \mathrm{W})-2.6952 \mathrm{E}-03 \\
& \mathrm{c}_{\mathrm{b}}=\mathrm{a}_{\mathrm{cb}} \cdot \beta^{2+} \mathrm{b}_{\mathrm{cb}} \cdot \beta+\mathrm{c}_{\mathrm{cb}} \\
& \mathrm{a}_{\mathrm{cb}}=-6.9194 \times 10^{-4} \cdot(\mathrm{y} / \mathrm{W})+2.6846 \mathrm{E}-04 \\
& \mathrm{~b}_{\mathrm{cb}}=7.8256 \times 10^{-2} \cdot(\mathrm{y} / \mathrm{W})+5.9363 \mathrm{E}-04 \\
& \mathrm{c}_{\mathrm{cb}}==2.0543 \cdot(\mathrm{y} / \mathrm{W})^{2}-6.2440 \times 10^{-3} \cdot(\mathrm{y} / \mathrm{W})-1.5349 \times 10^{-1}
\end{aligned}
$$

The units of $\beta$ and $\alpha$ are degrees. The parametric region where this solution is valid is: $\alpha \in\left[0,60^{\circ}\right] ; \mathrm{x} / \mathrm{W} \in[0.4,0.75$ $\mathrm{mm}] ; \mathrm{y} / \mathrm{W} \in[0,0.167]$. This solution has an average difference of $0.53 \%$ relative to numerical values, with maximum and minimum differences of +2.2 e -3.01 , respectively. The average difference was obtained from the absolute values of the differences.

Typical variations of geometric factor, $\mathrm{Y}_{\mathrm{II}}$, with $(\alpha-\beta), \beta$, y and $\mathrm{x}$ can be seen in Figs. 6a, 6b, 6c and 6d, respectively. $\mathrm{Y}_{\mathrm{II}}$ has a complex variation with $(\alpha-\beta)$ as can be seen in Fig. 6a. Minimum values, close to zero were obtained for $\alpha-\beta \approx 0$, as could be expected. As for $Y_{I}$, minimum values do not coincide exactly with $\alpha-\beta=0$, which is a consequence of the complexity of the situation. $\mathrm{Y}_{\mathrm{II}}$ increase with crack length, $\mathrm{x}$ (Fig. 6d). A good fitting to results in Figs. 6b ( $\beta$ ), 6c (y) and $6 \mathrm{~d}(\mathrm{x})$ was obtained with second order polynomials. The comparison between Figs. 6 indicates that the highest variation of $Y_{\text {II }}$ occur with $(\alpha-\beta)$, followed by $x$. The magnitudes of the variations of $Y_{\text {II }}$ with $x$ and $\beta$ are similar. The complex variations of $\mathrm{Y}_{\mathrm{II}}$, namely with $\alpha-\beta$, complicated significantly the development of a regression function.

Since similar values of $K_{I I}$ are expected for symmetrical values of $(\alpha-\beta)$, this parameter was replaced by $|\alpha-\beta|$. Besides since minimum values occur in general for $\alpha-\beta \neq 0$, $\mathrm{Y}_{\mathrm{II}}$ was studied as a function of $|(\alpha-\beta)-\tau|$, being $\tau$ the angle for minimum $\mathrm{Y}_{\mathrm{II}}$. Considering this change of independent variable and adequate values for $\tau$, the results of Fig. $6 \mathrm{a}$ modify to results in Fig. 7. All the results fall on the same trend, which indicates that the parameter proposed is adequate. An empirical expression with 54 constants was fitted to the numerical values of $\mathrm{Y}_{\mathrm{II}}$ :

$$
\begin{aligned}
& Y_{I I}=a \cdot \sin (|\alpha-\beta|-t) \\
& a=a_{a} \cdot(x / W)^{2}+b_{a} \cdot(x / W)+c_{a} \\
& a_{a}=a_{a a} \cdot \beta^{2}+b_{a a} \cdot \beta+c_{a a} \\
& a_{a a}=-1709 \cdot 472357 \cdot(y / W)^{2}+519.545852(y / W)+21.384622 \\
& b_{a a}=959.716917 \cdot(y / W)^{2}-249.236159(y / W)+6.561228 \\
& c_{a a}=-98.482311 \cdot(y / W)^{2}+4.234582(y / W)+1.006272 \\
& b_{a}=a_{b a} \cdot \beta^{2}+b_{b a} \cdot \beta+c_{b a} \\
& a_{b a}=1953.567396 \cdot(y / W)^{2}-541.35909(y / W)-19.747265 \\
& b_{b a}=-1101.79278 \cdot(y / W)^{2}+255.808188(y / W)-7.044048 \\
& c_{b a}=113.285142 \cdot(y / W)^{2}-3.803387(y / W)+0.704463
\end{aligned}
$$




$$
\begin{aligned}
& c_{a}=a_{c a} \cdot \beta^{2}+b_{c a} \cdot \beta+c_{c a} \\
& \mathrm{a}_{\mathrm{ca}}=-529.091514 \cdot(\mathrm{y} / \mathrm{W})^{2}+143.768493(\mathrm{y} / \mathrm{W})+4.296419 \\
& \mathrm{~b}_{\mathrm{ca}}=299.064879 .(\mathrm{y} / \mathrm{W})^{2}-71.861075(\mathrm{y} / \mathrm{W})+1.74509 \\
& \mathrm{c}_{\mathrm{ca}}=-27.688878 .(\mathrm{y} / \mathrm{W})^{2}+1.127385 .(\mathrm{y} / \mathrm{W})+0.773005 \\
& \mathrm{t}=\mathrm{a}_{\mathrm{t}} \cdot(\mathrm{x} / \mathrm{w})^{2}+\mathrm{b}_{\mathrm{t}} \cdot(\mathrm{x} / \mathrm{w})+\mathrm{c}_{\mathrm{t}} \\
& a_{t}=a_{a t} \cdot \beta^{2}+b_{a t} \cdot \beta+c_{a t} \\
& \mathrm{a}_{\mathrm{at}}=-31.328451 .(\mathrm{y} / \mathrm{W})^{2}-189.201651(\mathrm{y} / \mathrm{W})-13.342750 \\
& \mathrm{~b}_{\mathrm{at}}=-75.128472 \cdot(\mathrm{y} / \mathrm{W})^{2}+152.527046(\mathrm{y} / \mathrm{W})+11.48976 \\
& \mathrm{c}_{\mathrm{at}}=32.715576 .(\mathrm{y} / \mathrm{W})^{2}-17.576125(\mathrm{y} / \mathrm{W})-0.138782 \\
& b_{t}=a_{b t} \cdot \beta^{2}+b_{b t} \cdot \beta+c_{b t} \\
& a_{b t}=-15.361974 .(y / W)^{2}+209.112802(y / W)+11.726069 \\
& \mathrm{~b}_{\mathrm{bt}}=116.101593 .(\mathrm{y} / \mathrm{W})^{2}-166.317934(\mathrm{y} / \mathrm{W})-9.360830 \\
& \mathrm{c}_{\mathrm{bt}}=-41.982624 \cdot(\mathrm{y} / \mathrm{W})^{2}+19.603112(\mathrm{y} / \mathrm{W})+0.083306 \\
& c_{t}=a_{c t} \cdot \beta^{2}+b_{c t} \cdot \beta+c_{c t} \\
& \mathrm{a}_{\mathrm{ca}}=31.329018 .(\mathrm{y} / \mathrm{W})^{2}-53.553350(\mathrm{y} / \mathrm{W})-2.292627 \\
& \mathrm{~b}_{\mathrm{ca}}=-50.034429 \cdot(\mathrm{y} / \mathrm{W})^{2}+44.725843(\mathrm{y} / \mathrm{W})+1.819130 \\
& \mathrm{c}_{\mathrm{ct}}=12.967452 \cdot(\mathrm{y} / \mathrm{W})^{2}-5.665219(\mathrm{y} / \mathrm{W})-0.011360
\end{aligned}
$$

The units of $\beta, \alpha$ and $\tau$ are radians. The parametric region where this solution is valid is: $\alpha \in\left[0,60^{\circ}\right] ; \mathrm{x} / \mathrm{W} \in[0.4,0.75$ $\mathrm{mm}] ; \mathrm{y} / \mathrm{W} \in[0,0.167]$. This solution has an average difference of $10.8 \%$ relatively to the numerical values. This average was once again calculated using the absolute values of the differences. This difference is relatively high, however it is mainly a consequence of odd results obtained for a reduced number of the predictions.
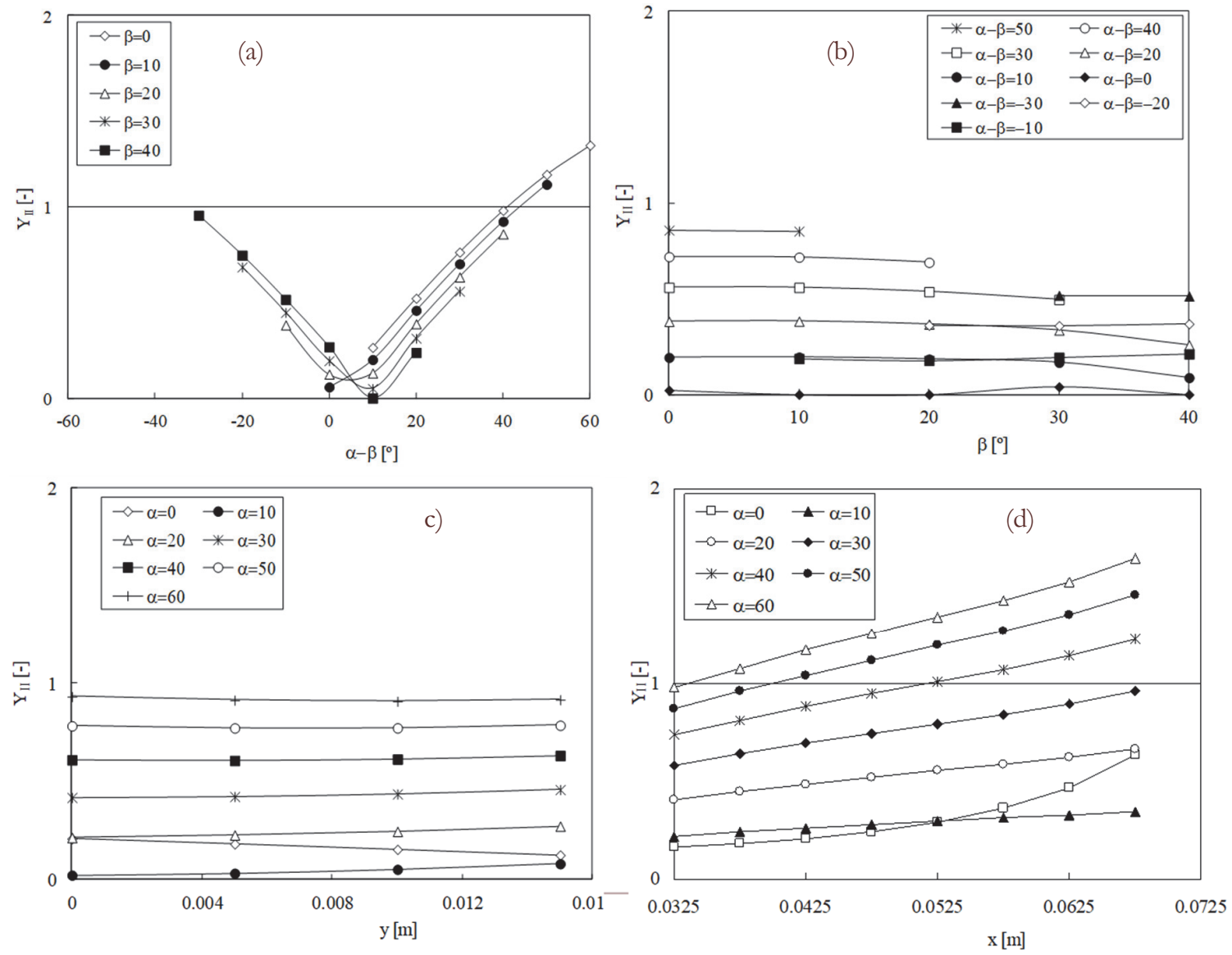

Figure 6: Variation of $Y_{I I}$ with (a) $(\alpha-\beta)$ (for $x=52.5 \mathrm{~mm} ; \mathrm{y}=0$ ). (b) $\operatorname{crack}$ tip slope $(\beta)$ (for $\mathrm{x}=32.5 \mathrm{~mm}$; $\left.y=0\right)$. (c) yp. (d) $x$ P (for $y=5$ $\left.\mathrm{mm} ; \beta=10^{\circ}\right)$. 


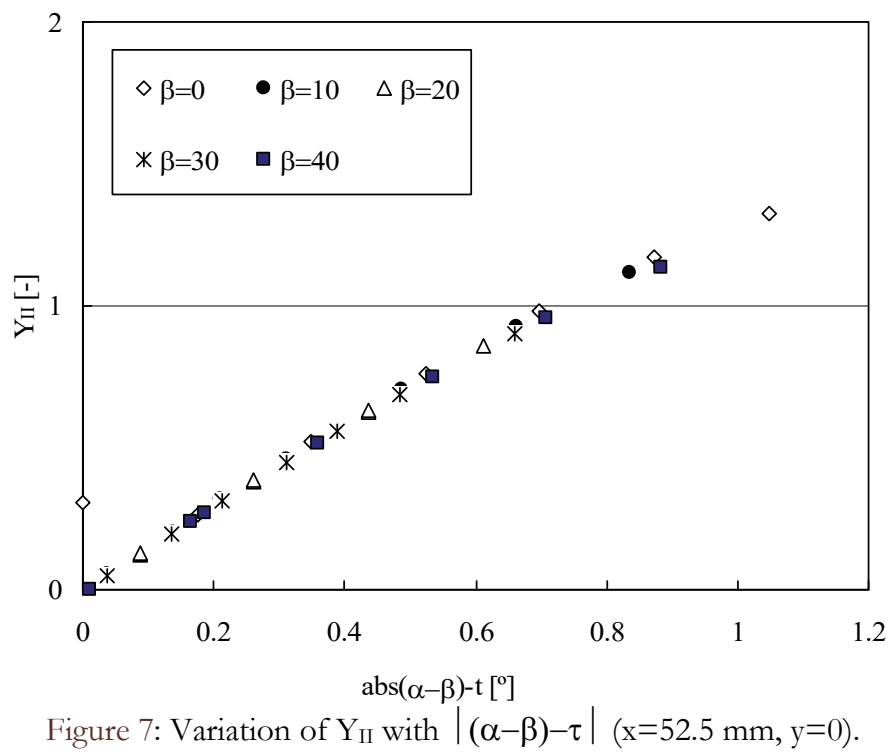

Furthermore, to evaluate the characteristics of mixed mode fatigue crack, it is necessary to introduce the comparative stress intensity factor $\mathrm{K}_{\mathrm{v}}$ considering mode I and mode II simultaneously. The exact relation between $\mathrm{K}_{\mathrm{v}}, \mathrm{K}_{\mathrm{I}}$ and $\mathrm{K}_{\mathrm{II}}$ depends on the criterion employed. The criterion of Richard/Henn [18] proposes:

$$
\Delta \mathrm{K}_{\mathrm{V}}=\frac{\Delta \mathrm{K}_{\mathrm{I}}}{2}+\frac{1}{2} \sqrt{\Delta \mathrm{K}_{\mathrm{I}}^{2}+6 \Delta \mathrm{K}_{\mathrm{II}}^{2}}
$$

The values of $\mathrm{K}_{\mathrm{II}}$ are in general much lower than the ones obtained for $\mathrm{K}_{\mathrm{I}}$, therefore its influence on $\mathrm{K}_{\mathrm{V}}$ defined by eq. (8) is relatively low.

The solutions presented here for $Y_{I}$ and $Y_{I I}$ were used to obtain $K_{V}$ and this was compared with $K_{v}$ obtained directly from CosmosM results. Maximum and minimum differences were found to be +10.63 and $-4.5 \%$ respectively, but the average difference is $1.01 \%$, which is excellent.

\section{EXPERIMENTAL FATIGUE RESULTS}

A

n experimental work was developed to study fatigue crack growth and fatigue crack closure under mixed mode loading in 6082-T6 aluminium alloy. The specimens were obtained in the transverse longitudinal (TL) direction from a laminated plate. The initial notch depth was $42.5 \mathrm{~mm}$. Before testing the specimen surfaces were polished mechanically. The experiments were performed in a servo-hydraulic, closed-loop mechanical test machine with $100 \mathrm{kN}$ load capacity, interfaced to a computer for machine control and data acquisition. All tests were conducted in air and at room temperature. The tests were performed under load control mode and the load ratio for all loading angles was kept constant at 0.05 . The loads were applied with a sinusoidal waveform at a frequency of $20 \mathrm{~Hz}$. Fatigue pre-cracking was introduced under mode-I loading to an a/W ratio of 0.51 , where a and $\mathrm{W}$ are the crack length and width of the specimen, respectively. The crack length was measured in both $\mathrm{x}$ and $\mathrm{y}$ directions using a travelling microscope (45x) with a resolution of $10 \mu \mathrm{m}$. The specimen was painted ahead of the crack tip (Fig. 2) to enhance optical measurement of crack length.

The maximum and minimum loads applied for each loading angle were chosen in order to have after fatigue pre-crack a comparative stress intensity factor, $\Delta \mathrm{K}_{\mathrm{V}}$, defined by eq. (8) of approximately $6 \mathrm{MPa} \cdot \mathrm{m}^{1 / 2}$, where the mode-I and mode-II stress intensity factor ranges were calculated by the solutions presented in Appendix A. Tab. 3 summarizes the parameters of the experimental testes. Further details can be found elsewhere [3]. The K solutions developed here were applied to the treatment of the experimental results.

The crack tip coordinates $(\mathrm{x}, \mathrm{y})$ and slope, $\beta$, were measured directly on specimen's surface using Profilometer Rodenstok RM 6003D. However, $\beta$ could have been obtained from $(x, y)$ values using a procedure similar to the calculation of $d a / d N$ 
from $(a, N)$ experimental results. Fig. 8 presents experimental crack shapes for different loading directions, which are indicated for each case. The cracks adopted a direction approximately normal to loading direction, i.e., tend to propagate under mode I loading. However, $(\alpha-\beta)$ is not exactly zero and increases with $\alpha$ and with crack length.

\begin{tabular}{cccc}
\hline Test & $\alpha\left[{ }^{\circ}\right]$ & $\Delta \mathrm{F}[\mathrm{N}]$ & $\mathrm{R}$ \\
1 & 30 & 1539 & 0.05 \\
2 & 45 & 1900 & 0.05 \\
3 & 60 & 2043 & 0.05 \\
4 & 76 & 2394 & 0.05 \\
\hline
\end{tabular}

Table 3: Experimental parameters used in the tests.

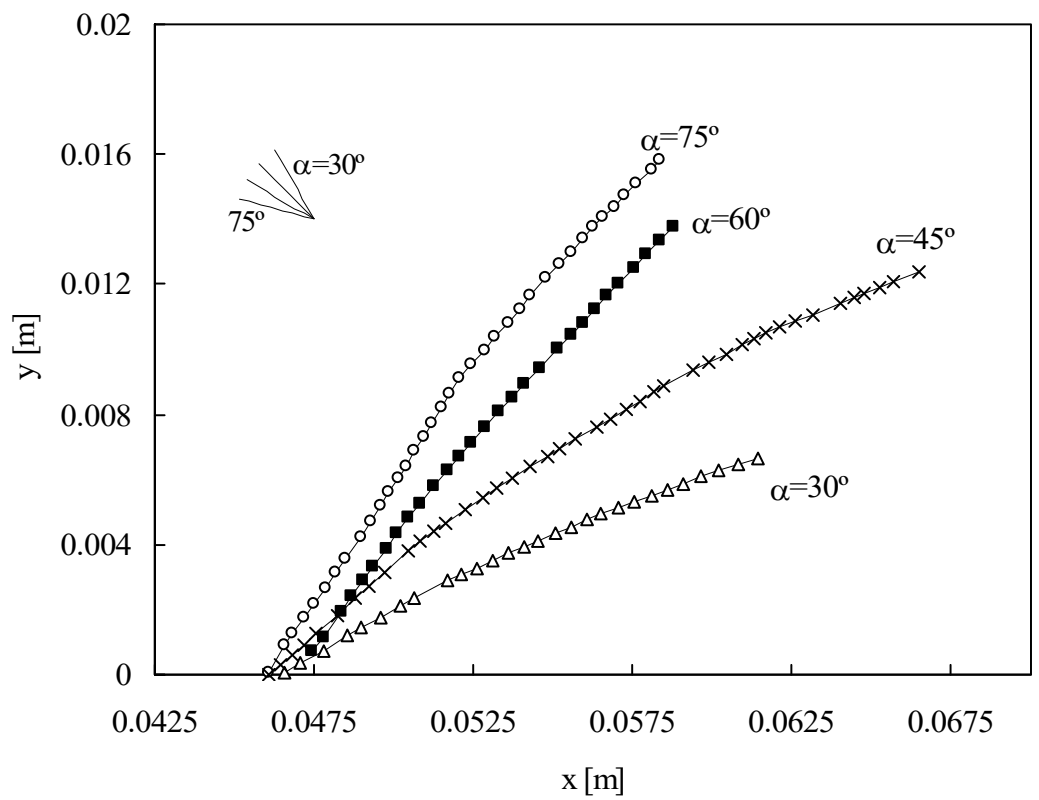

Figure 8: Experimental crack shapes.

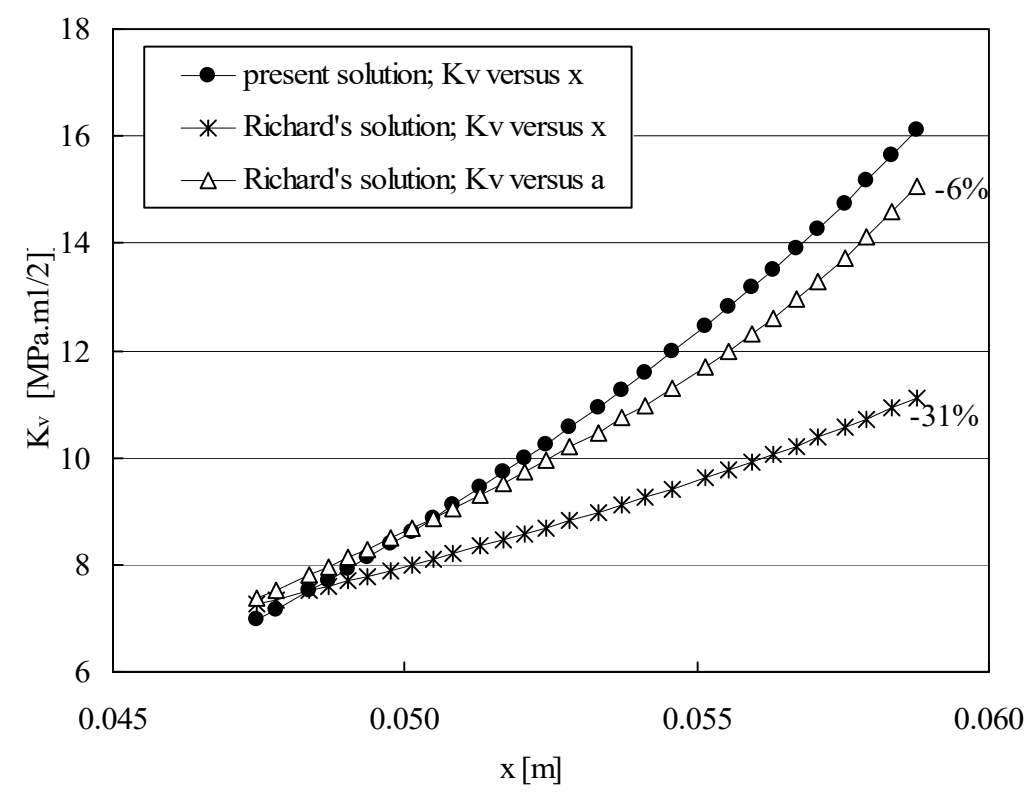

Figure 9: Comparison of present solution with Richard's solution $\left(\alpha=60^{\circ}\right)$. 
The values of $\mathrm{x}, \mathrm{y}, \alpha, \beta$ were applied in solutions 6 and 7 to obtain $\mathrm{Y}_{\mathrm{I}}$ and $\mathrm{Y}_{\mathrm{II}}$, respectively. Then considering experimental loads presented in Tab. 3, $K_{I}$ and $K_{I I}$ were calculated. Finally, effective stress intensity factor was obtained using Eqn. 8. Fig. 9 compares the values of $K_{v}$ for $\alpha=60^{\circ}$ obtained with solutions 6 and 7 , and with Richard's solution. Two different approaches were considered when applying Richard's solution: consider $\mathrm{x}$ and consider crack length, a. Significant differences were found, with maximum values of $-6 \%$ and $-31 \%$, as indicated in Fig. 9. Differences are significantly reduced if total crack length, a, is used in Richard's solution instead of coordinate $\mathrm{x}$. Therefore, the present solution represents a significant improvement relatively to Richard's solution. Notice that Richard's solution was obtained for $y=0$ and $\beta=0^{\circ}$.

\section{NUMERICAL PREDICTION OF CRACK PATH}

$\mathrm{P}$

ropagation directions were also studied numerically using the solutions developed here for $\mathrm{Y}_{\mathrm{I}}$ and $\mathrm{Y}_{\mathrm{II}}$. Qian et al. [19] reviewed the criteria used to predict crack growth direction under mixed mode loading, which can be divided into two categories [20]. The first includes the methodologies which consider the stress, the strain or the displacement as the driving parameters, namely the Maximum Tangential Stress criterion (MTS criterion), and the vector crack tip displacement criterion (CTD criterion). The second category contains the methodologies considering the total or the dilatational elastic strain as the driving parameters, namely the minimum strain energy density criteria (S- criterion), the dilatational strain energy density criterion (T-Criterion), the minimum accumulated elastic strain energy (P-criterion) and the J-criterion. The MTS and S criteria are widely used. According S-criterion [21] the crack is assumed to grow along a direction that minimizes the strain energy density factor, S:

$$
\mathrm{S}=\mathrm{a}_{11} \mathrm{k}_{1}^{2}+2 \mathrm{a}_{12} \mathrm{k}_{1} \mathrm{k}_{2}+\mathrm{a}_{22} \mathrm{k}_{2}^{2}+\mathrm{a}_{33} \mathrm{k}_{3}^{2}
$$

where $a_{i j}$ are coefficients relating polar angle $(\theta), E$ and $v$, and $k_{i}=K_{i} / \sqrt{\pi} . S$ includes the dilatational and the distortional strain energy. The J-criterion uses the line integral with the same name and states that crack extends along direction of vector:

$$
\vec{J}=\mathrm{J}_{\mathrm{I}} \cdot \hat{\mathrm{i}}+\mathrm{J}_{\mathrm{II}} \cdot \hat{\mathrm{j}}
$$
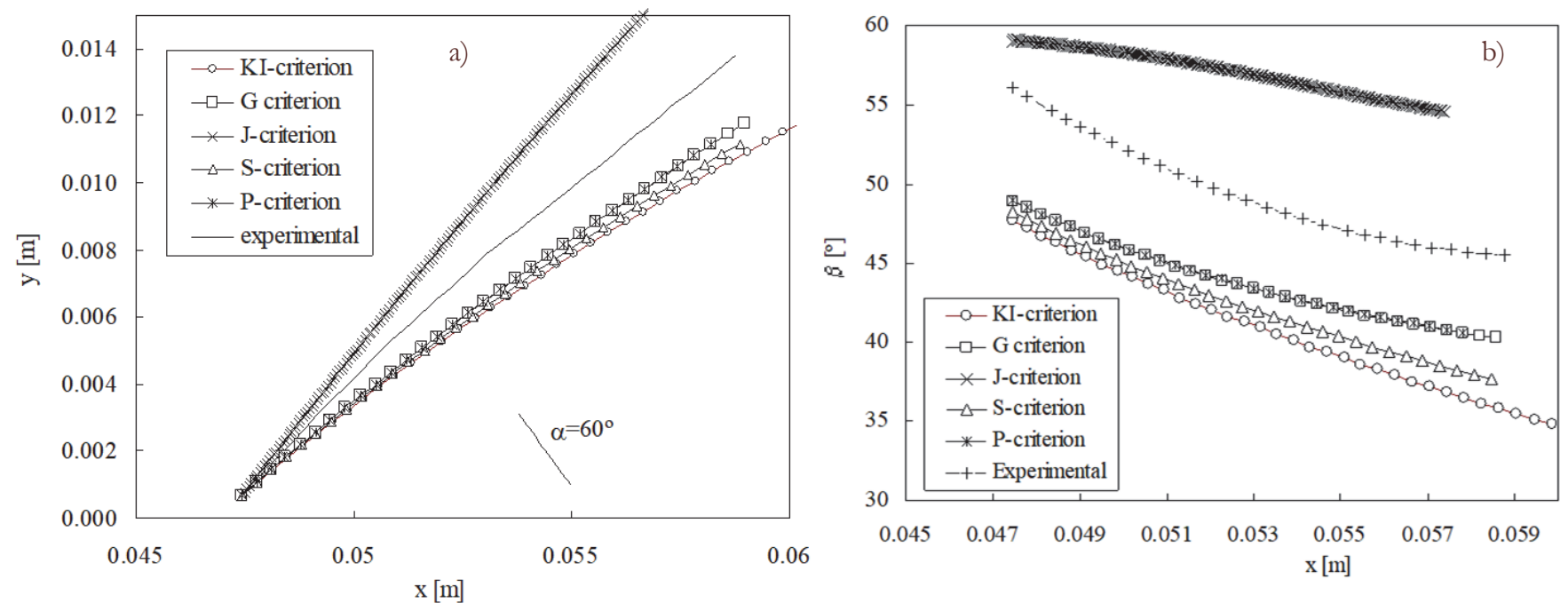

Figure 10: (a) Crack direction predictions considering different criteria $\left(\alpha=60^{\circ}\right)$. (b) Crack tip slopes $(\beta)$ for different crack propagation criteria $\left(\alpha=60^{\circ}\right)$.

Notice that since $\mathrm{K}$ solutions were defined in terms of $(\alpha-\beta)$, crack propagation increments must consider a rotation of Cartesian coordinate system. In fact, $\mathrm{J}_{\mathrm{II}}=0$ corresponds to a propagation along a direction normal to loading direction. 
The P-criterion [20] considers the accumulated elastic strain energy $(\mathrm{P})$ within a circular core with radius $\mathrm{r}_{0}$ around the crack tip as the driving parameter. P-factor is given by:

$$
\mathrm{P}=\lambda_{1} \mathrm{~K}_{\mathrm{I}}^{2}+\lambda_{3} \mathrm{~K}_{\mathrm{II}}^{2}
$$

being $\lambda_{1}=0.0000191419$ and $\lambda_{3}=0.0000300746$, as indicated by Pavlou et al. [20]. The crack is assumed to propagate along direction of minimum P-factor. Another two criteria were used here: the maximum value of $\mathrm{K}_{\mathrm{I}}\left(\mathrm{K}_{\mathrm{I}}\right.$-criterion) and the minimum value of energy release rate (G-criterion), being $G$ obtained from effective stress intensity factor defined in Eqn. 8. Fig. 10a presents the results obtained for $\alpha=60^{\circ}$ considering different criteria and crack propagation increments of 0.5 $\mathrm{mm}$. Loading direction is also presented. It can be seen that all criteria, except J-criterion, predict crack slopes lower than experimentally observed. Best predictions were obtained with P-criterion and G criterion, which gave similar results. Finally, Fig. 10b presents the variation of crack tip slope $(\beta)$ with crack propagation. It can be seen that $\beta$ reduces with crack propagation. The rate of variation of $\beta$ with crack growth predicted numerically is similar to that measured experimentally.

\section{CONCLUSIONS}

7 he main conclusions of the present work are:

- $\mathrm{K}_{\mathrm{I}}, \mathrm{K}_{\mathrm{II}}$ stress intensity factor solutions were obtained numerically for CTS (Compact Tension Shear) specimen.

These solutions are valid for a wide range of $\mathrm{x}, \mathrm{y}, \alpha$ (load direction) and $\beta$ (crack tip angle): $\alpha \in\left[0,60^{\circ}\right] ; \mathrm{x} / \mathrm{W} \in$ $[0.4,0.75 \mathrm{~mm}] ; \mathrm{y} / \mathrm{W} \in[0,0.167]$.

- The average accuracy of $\mathrm{K}_{\mathrm{V}}$ is expected to be $1.01 \%$;

- The solution developed was applied to crack profiles obtained experimentally in 6082-T6 aluminium alloy. As expected, significant differences were found between present solution and Richard's solution when $\alpha$ is different from zero. The differences reduce significantly when the whole crack length is used in Richard's solution;

- Experimental work was developed to study fatigue crack growth in CTS specimens. The cracks always adopted a direction approximately normal to loading direction, i.e., tend to propagate under mode I loading;

- The solution developed here was used to predict crack growth direction considering different criteria. Best predictions were obtained with P-criterion and G-criterion.

By request the authors will send by e-mail the solution developed here, implemented in an Excel file.

\section{AKNOWLEDGEMENTS}

7 his research is sponsored by FEDER funds through the program COMPETE (under project T44950814400019113) and by national funds through FCT - Portuguese Foundation for Science and Technology, under the project PTDC/EMS-PRO/1356/2014.

\section{REFERENCES}

[1] Richard, H.A. (1981). A new compact shear specimen, International Journal of Fracture, 17, pp. R105-R107.

[2] Biner, S.B. (2001). Fatigue Crack Growth Studies Under Mixed-mode Loading, International Journal of Fatigue, 23, pp. S259-S263.

[3] Borrego, L.P., Antunes, F.V., Ferreira, J.M. and Costa, J.D. (2004). Mixed-mode fatigue crack growth and closure in aluminium alloys, Proc. 7th ICBMFF- Seventh International Conference on Biaxial/Multiaxial Fatigue \& Fracture, Berlin, Germany, pp.1483-488.

[4] Rikards, R. et al. (1998). Investigation of mixed Mode I/II Interlaminar Fracture Toughness of Laminated Composites by Using a CTS Type Specimen, Engineering Fracture Mechanics, 61, pp. 325-342.

[5] Madhusudhana, K.S. and Narasimhan, R. (2002). Experimental and numerical investigations of mixed mode crack growth resistance of a ductile adhesive joint, Engineering Fracture Mechanics, 69, pp. 865-883. 
[6] Pirondi, A. and Nicoletto, G. (2002). Mixed Mode I/II Fracture Toughness of Bonded Joints, International Journal of Adhesion and Adhesives, 22, pp. 109-117.

[7] Lin, G.-Y. and Shetty, D.K. (2003). Transformation Zones, Crack Shielding, and Crack Growth Resistance of CeTZP/Alumina Composite in Mode II and Combined Mode II and Mode I Loading, Engineering Fracture Mechanics, 70, pp. 2569-2585.

[8] Banks-Sills, L. and Arcan, M. (1986). A compact mode II fracture specimen, Fracture Mechanics, 17, ASTM-STP 905, American Society for Testing and Materials, pp. 347-363.

[9] Lo, K.W., Gong, Y.B., Tamilselvan, T. and Lai, M.O. (2003). A proposed specimen for KIIC testing, International Journal of Fracture, 124, pp. 127-137.

[10] Hyde, T.H. and Chambers, A.C. (1988). A compact mixed-mode (CMM) fracture specimen, Journal of Strain Analysis, 23 (2), pp. 61-66.

[11] Choi, R.S., Zhu, D. and Miller, R.A. (2003). Mode I, mode II and mixed-mode fracture of plasma-sprayed thermal barrier coatings at ambient and elevated temperatures, Proc. 8th International Symposium on Fracture Mechanics of Ceramics, University of Houston, (NASA/TM 2003-212185).

[12] Patterson, E.A. and Gungor, S. (1997). A photoelastic study of an angle crack specimen subjected to mixed mode IIII displacements, Engineering Fracture Mechanics, 56, pp. 767-778.

[13] Ayatollahi, M.R. and Aliha, M.R.M. (2005). Cracked Brazilian disc specimen subjected to mode II deformation, Engineering Fracture Mechanics, 75, pp. 493-503.

[14] Lardender, T.J., Chakravarthy, J.D., Quinn, J.D. and Ritter, J.E. (2001). Further analysis of DCDC specimen with an offset hole, International Journal of Fracture, 109, pp. 227-237.

[15] Richard, H.A. and Benitz, K. (1983). A loading device for the creation of mixed mode in fracture mechanics, International Journal of Fracture, 22, pp. R55-R58.

[16] Richard, H.A. (1985). Bruchvorhersagen bei überlagerter normal- und schubbeanspruchung von risen, VDI Forschungsheft 631, Düsseldorf: VDI-Verlag, pp. 1-60.

[17] Setién, J. and Varona, J.M. (1996). On the Use of Dimensional Analysis in Fracture Mechanics. Proc. 11th Biennial European Conference on Fracture (ECF11), Poitiers, France, Ed. by J. Petit, Vol.I, September 3-6, pp. 125-132.

[18] Richard, H.A., Linnig, W. and Henn, K. (1991). Fatigue crack propagation under combined loading, Forensic Engineering, 3, pp. 99-109.

[19] Qian, J. and Fatemi, A. (1996). Mixed mode fatigue crack: a literature survey, Engineering Fracture Mechanics, 55 (6), pp. 969-990.

[20] Pavlou, D.G. Labeas, G.N., Vlachakis, N.V. and Pavlou, F.G. (2003). Fatigue crack propagation trajectories under mixed mode cycling loading, Engineering Structures, 25, pp. 869-875.

[21] Sih, G.C. (1974). Strain energy density factor applied to mixed mode crack problems, International Journal of Fracture, 10, pp. 305-321.

\section{APPENDIX A: LITERATURE SOLUTION [15]}

he stress intensity factors for different loading angles considering $\beta=0^{\circ}$ are:

$$
\begin{aligned}
& \mathrm{K}_{\mathrm{I}}=\frac{\mathrm{F}}{\mathrm{W} . \mathrm{t}} \sqrt{\pi \cdot \mathrm{a}} \frac{\cos \alpha}{1-\mathrm{a} / \mathrm{W}} \sqrt{\frac{0.26+2.65 \frac{\mathrm{a}}{\mathrm{W}-\mathrm{a}}}{1+0.55 \frac{\mathrm{a}}{\mathrm{W}-\mathrm{a}}-0.08\left(\frac{\mathrm{a}}{\mathrm{W}-\mathrm{a}}\right)^{2}}} \\
& \mathrm{~K}_{\mathrm{II}}=\frac{\mathrm{F}}{\mathrm{W} . \mathrm{t}} \sqrt{\pi \cdot \mathrm{a}} \frac{\sin \alpha}{1-\mathrm{a} / \mathrm{W}} \sqrt{\frac{-0.23+1.40 \frac{\mathrm{a}}{\mathrm{W}-\mathrm{a}}}{1-0.67 \frac{\mathrm{a}}{\mathrm{W}-\mathrm{a}}+2.08\left(\frac{\mathrm{a}}{\mathrm{W}-\mathrm{a}}\right)^{2}}}
\end{aligned}
$$


where $\mathrm{F}$ is the applied force, $\mathrm{W}$ is the width of the specimen, $\mathrm{t}$ is the thickness, $\mathrm{a}$ is the crack length, $\alpha$ is the angle of loading direction with respect to the crack plane. The degree of the mode-mixity is given by:

$$
\mathrm{M}=\frac{2}{\pi} \cdot \operatorname{a} \cdot \tan \left(\frac{\mathrm{K}_{\mathrm{I}}}{\mathrm{K}_{\mathrm{II}}}\right)
$$




\section{APPENDIX B: NUMERICAL RESULTS}

\begin{tabular}{|c|c|c|c|c|c|c|c|c|c|c|c|c|c|c|c|}
\hline & & & & $x=$ & 32.5 & & & & & & $x=$ & 37.5 & & & \\
\hline & $\beta^{\alpha}$ & 0 & 10 & 20 & 30 & 40 & 50 & 60 & 0 & 10 & 20 & 30 & 40 & 50 & 60 \\
\hline & 0 & 1.97 & 1.91 & 1.8 & 1.63 & 1.41 & 1.15 & 0.86 & 2.27 & 2.22 & 2.1 & 1.91 & 1.67 & 1.37 & 1.04 \\
\hline & 10 & 1.94 & 1.94 & 1.87 & 1.75 & 1.58 & 1.35 & 1.09 & 2.24 & 2.24 & 2.18 & 2.04 & 1.85 & 1.6 & 1.3 \\
\hline$y=0$ & 20 & 1.87 & 1.91 & 1.9 & 1.82 & 1.7 & 1.52 & 1.29 & 2.16 & 2.22 & 2.2 & 2.12 & 1.98 & 1.77 & 1.51 \\
\hline & 30 & 1.76 & 1.84 & 1.87 & 1.85 & 1.76 & 1.62 & 1.44 & 2.04 & 2.14 & 2.17 & 2.14 & 2.05 & 1.89 & 1.68 \\
\hline & 40 & 1.6 & 1.72 & 1.79 & 1.81 & 1.76 & 1.67 & 1.52 & 1.87 & 2.01 & 2.09 & 2.1 & 2.06 & 1.95 & 1.78 \\
\hline & 0 & 1.97 & 1.99 & 1.94 & 1.84 & 1.68 & 1.46 & 1.21 & 2.28 & 2.3 & 2.25 & 2.13 & 1.95 & 1.71 & 1.42 \\
\hline & 10 & 1.95 & 2.02 & 2.02 & 1.96 & 1.84 & 1.67 & 1.44 & 2.25 & 2.33 & 2.34 & 2.27 & 2.13 & 1.94 & 1.68 \\
\hline$y=5$ & 20 & 1.89 & 2 & 2.04 & 2.03 & 1.96 & 1.82 & 1.63 & 2.18 & 2.31 & 2.36 & 2.35 & 2.26 & 2.1 & 1.88 \\
\hline & 30 & 1.78 & 1.93 & 2.02 & 2.05 & 2.01 & 1.92 & 1.77 & 2.06 & 2.23 & 2.33 & 2.36 & 2.32 & 2.21 & 2.03 \\
\hline & 40 & 1.63 & 1.81 & 1.93 & 2 & 2 & 1.95 & 1.83 & 1.9 & 2.1 & 2.24 & 2.32 & 2.32 & 2.25 & 2.11 \\
\hline & 0 & 1.98 & 2.07 & 2.09 & 2.05 & 1.94 & 1.78 & 1.56 & 2.29 & 2.39 & 2.41 & 2.37 & 2.25 & 2.06 & 1.81 \\
\hline & 10 & 1.97 & 2.1 & 2.17 & 2.18 & 2.11 & 1.99 & 1.8 & 2.28 & 2.43 & 2.51 & 2.51 & 2.43 & 2.29 & 2.07 \\
\hline$y=10$ & 20 & 1.91 & 2.09 & 2.2 & 2.25 & 2.23 & 2.14 & 1.98 & 2.21 & 2.41 & 2.54 & 2.59 & 2.56 & 2.45 & 2.27 \\
\hline & 30 & 1.81 & 2.02 & 2.18 & 2.26 & 2.28 & 2.23 & 2.11 & 2.1 & 2.37 & 2.51 & . & 2.62 & 2.55 & 2.41 \\
\hline & 40 & 1.66 & 1.91 & 2.09 & 2.21 & 2.26 & 2.24 & 2.16 & 1.94 & 2.21 & 2.42 & 2.55 & 2.6 & 2.57 & 2.47 \\
\hline & 0 & 2.01 & 2.16 & 2.25 & 2.27 & 2.23 & 2.11 & 1.93 & 2.32 & 2.49 & 2.59 & 2.62 & 2.56 & 2.42 & 2.22 \\
\hline & 10 & 2 & 2.2 & 2.34 & 2.41 & 2.4 & 2.32 & 2.17 & 2.31 & 2.54 & 2.69 & 7 & 2.75 & 2.66 & 2.48 \\
\hline$y=15$ & 20 & 1.95 & 2.2 & 2.38 & 2.48 & 2.52 & 2.47 & 2.35 & 2.25 & 2.53 & 2.73 & 2.85 & 2.88 & 2.82 & 2.68 \\
\hline & 30 & 1.85 & 2.13 & 2.35 & 2.5 & 2.56 & 2.56 & 2.47 & 2.14 & 2.46 & 2.7 & 2.86 & 2.93 & 2.92 & 2.81 \\
\hline & 40 & 1.71 & 2.02 & 2.26 & 2.43 & 2.53 & 2.56 & 2.5 & 1.99 & 2.34 & 2.61 & 2.8 & 2.91 & 2.93 & 2.86 \\
\hline & & & & $x=$ & 42.5 & & & & & & $x=$ & 47.5 & & & \\
\hline & $\beta^{\alpha}$ & 0 & 10 & 20 & 30 & 40 & 50 & 60 & 0 & 10 & 20 & 30 & 40 & 50 & 60 \\
\hline & 0 & 2.64 & 2.59 & 2.46 & 2.25 & 1.98 & 1.64 & 1.26 & 3.14 & 3.09 & 2.94 & 2. & 2.38 & 1.98 & 1.53 \\
\hline & 10 & 2.61 & 2.62 & 2.55 & 2.39 & 2.17 & 1.88 & 1.53 & 3.11 & 3.11 & 3.03 & 2.85 & 2.58 & 2.24 & 1.83 \\
\hline$y=0$ & 20 & 2.52 & 2.59 & 2.57 & 2.47 & 2.3 & 2.07 & 1.76 & 3 & 3.07 & 3.04 & 2.93 & 2.72 & 2.43 & 2.07 \\
\hline & 30 & 2.38 & 2.49 & 2.53 & 2.49 & 2.37 & 2.19 & 1.93 & 2.83 & 2.96 & 2.99 & 2.93 & 2.78 & 2.55 & 2.24 \\
\hline & 40 & 2.19 & 2.34 & 2.43 & 2.44 & 2.37 & 2.24 & 2.03 & 2.61 & 2.78 & 2.86 & 2.86 & 2.77 & 2.59 & 2.34 \\
\hline & 0 & 2.65 & 2.68 & 2.63 & 2.5 & 2.29 & 2.01 & 1.67 & 3.15 & 3.18 & 3.12 & 2.97 & 2.72 & 2.4 & 1.99 \\
\hline & 10 & 2.63 & 2.71 & 2.72 & 2.64 & 2.48 & 2.25 & 1.95 & 3.12 & 3.22 & 3.22 & 3.12 & 2.93 & 2.65 & 2.29 \\
\hline$y=5$ & 20 & 2.54 & 2.68 & 2.74 & 2.72 & 2.62 & 2.43 & 2.17 & 3.02 & 3.18 & 3.24 & 3.2 & 3.07 & 2.84 & 2.53 \\
\hline & 30 & 2.4 & 2.59 & 2.7 & 2.73 & 2.68 & 2.54 & 2.33 & 2.86 & 3.07 & 3.18 & 3.2 & 3.12 & 2.95 & 2.68 \\
\hline & 40 & 2.22 & 2.45 & 2.6 & 2.67 & 2.66 & 2.57 & 2.41 & 2.65 & 2.89 & 3.05 & 3.12 & 3.09 & 2.97 & 2.76 \\
\hline & 0 & 2.67 & 2.78 & 2.81 & 2.75 & 2.61 & 2.39 & 2.1 & 3.16 & 3.29 & 3.32 & 3.25 & 3.08 & 2.82 & 2.47 \\
\hline & 10 & 2.65 & 2.82 & 2.91 & 2.91 & 2.82 & 2.64 & 2.38 & 3.15 & 3.34 & 3.43 & 3.42 & 3.3 & 3.08 & 2.77 \\
\hline$y=10$ & 20 & 2.57 & 2.8 & 2.94 & 2.99 & 2.95 & 2.82 & 2.6 & 3.06 & 3.31 & 3.45 & 3.5 & 3.44 & 3.27 & 3 \\
\hline & 30 & 2.44 & 2.71 & 2.9 & 2.99 & 3 & 2.92 & 2.74 & 2.9 & 3.2 & 3.4 & 3.49 & 3.48 & 3.37 & 3.15 \\
\hline & 40 & 2.26 & 2.56 & 2.79 & 2.93 & 2.98 & 2.93 & 2.8 & 2.69 & 3.03 & 3.27 & 3.41 & 3.44 & 3.38 & 3.21 \\
\hline & 0 & 2.7 & 2.9 & 3.01 & 3.03 & 2.96 & 2.8 & 2.55 & 3.2 & 3.42 & 3.55 & 3.56 & 3.47 & 3.27 & 2.97 \\
\hline & 10 & 2.69 & 2.95 & 3.12 & 3.19 & 3.17 & 3.05 & 2.84 & 3.19 & 3.48 & 3.66 & 3.74 & 3.7 & 3.55 & 3.29 \\
\hline$y=15$ & 20 & 2.62 & 2.93 & 3.15 & 3.28 & 3.31 & 3.23 & 3.06 & 3.11 & 3.45 & 3.7 & 3.83 & 3.84 & 3.74 & 3.52 \\
\hline & 30 & 2.5 & 2.85 & 3.12 & 3.29 & 3.36 & 3.33 & 3.19 & 2.96 & 3.35 & 3.64 & 3.82 & 3.89 & 3.83 & 3.66 \\
\hline & 40 & 2.33 & 2.71 & 3.01 & 3.21 & 3.32 & 3.33 & 3.24 & 2.76 & 3.18 & 3.51 & 3.73 & 3.84 & 3.83 & 3.7 \\
\hline
\end{tabular}




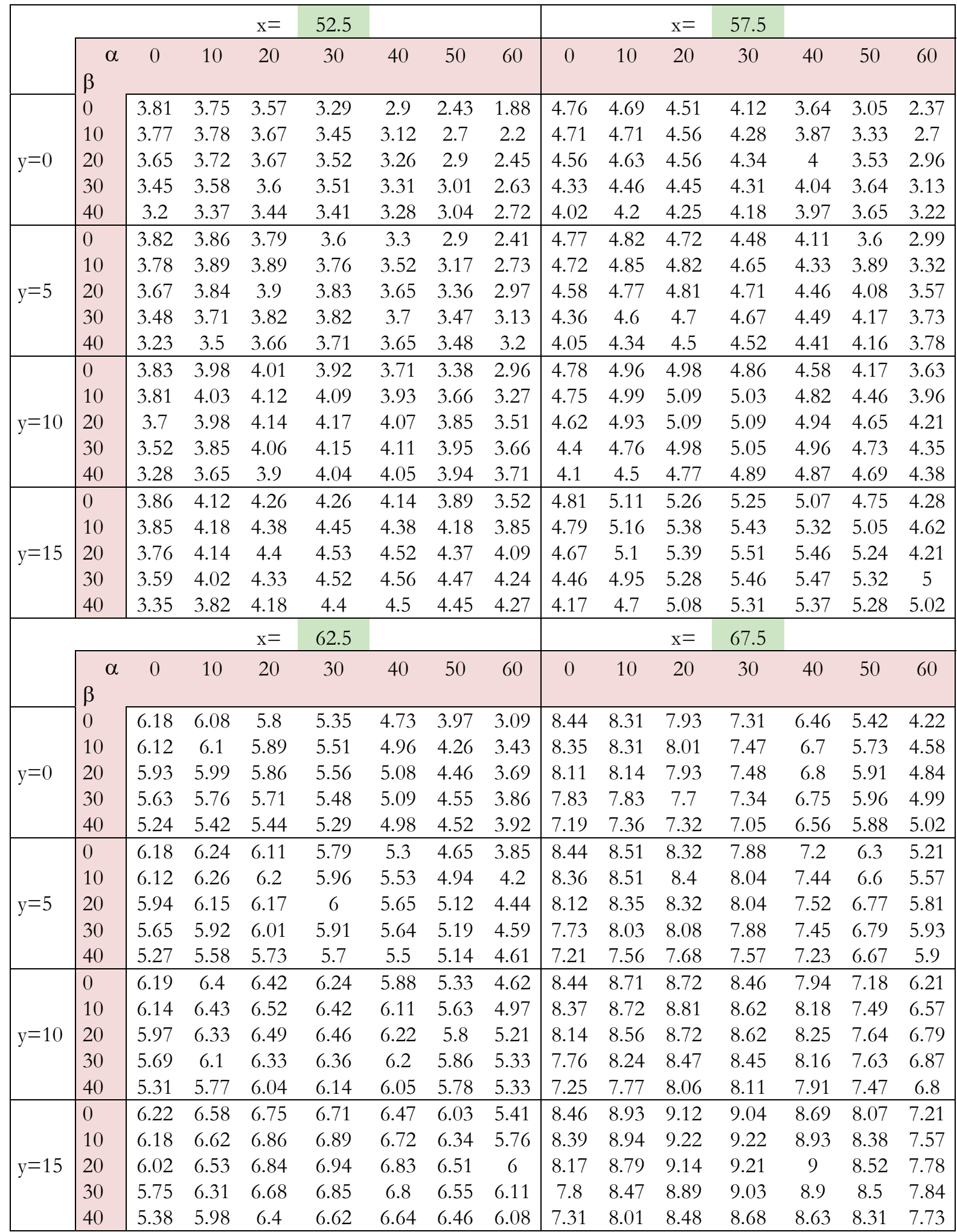

Table B1: Numerical values obtained for $\mathrm{Y}_{\mathrm{I}}$. 


\begin{tabular}{|c|c|c|c|c|c|c|c|c|c|c|c|c|c|c|c|}
\hline & & & & $x=$ & 32.5 & & & & & & $x=$ & 37.5 & & & \\
\hline & $\beta^{\alpha}$ & 0 & 10 & 20 & 30 & 40 & 50 & 60 & 0 & 10 & 20 & 30 & 40 & 50 & 60 \\
\hline \multirow{5}{*}{$y=0$} & 0 & 0.02 & 0.19 & 0.38 & 0.56 & .72 & 0.86 & 0.97 & 0 & 0.21 & 0.42 & 0.02 & 0.79 & ד. & 1.07 \\
\hline & 10 & 0.19 & 0 & 0.19 & 0.38 & .56 & 0.72 & 0.85 & 0.21 & 0.02 & 0.22 & 0.42 & 0.61 & 8 & 0.93 \\
\hline & 20 & 0.36 & 0.18 & 0 & 0.18 & 0.37 & 0.54 & 0.69 & 0.41 & 0.21 & 0.05 & 0.2 & 0.4 & 0.58 & 0.75 \\
\hline & 30 & 0.52 & 0.36 & 0.19 & 0.04 & 0.17 & 0.34 & 0.5 & 0.58 & 0.41 & 0.23 & 0.05 & 0.17 & 0.35 & 0.53 \\
\hline & 40 & 0.64 & 0.51 & 0.37 & 0.21 & 0 & 0.09 & 0.26 & 0.72 & 0.58 & 0.43 & 0.26 & 0.08 & 0.11 & 0.28 \\
\hline \multirow{5}{*}{$y=5$} & 0 & 0.03 & 0.22 & 0.4 & 0.58 & .74 & 0.87 & 0.98 & 0.38 & 0.24 & 0.45 & 0.64 & 0.81 & 0.96 & 1.08 \\
\hline & 10 & 0.16 & 0 & 0.21 & 0.39 & 0.56 & 0.71 & 0.84 & 0.18 & 0.03 & 0.23 & 0.42 & 0.61 & 0.77 & 0.91 \\
\hline & 20 & 0.34 & 0.17 & 0 & 0.17 & 0.34 & 0.5 & 0.65 & 0.38 & 0.2 & 0.05 & 0.19 & 0.38 & 0.55 & 0.7 \\
\hline & 30 & 0.5 & 0.36 & 0.21 & 0.06 & 0.13 & 0.28 & 0.43 & 0.56 & 0.4 & 0.24 & 0.08 & .13 & 0.29 & 0.46 \\
\hline & 40 & 0.63 & 0.52 & 0.39 & 0.25 & 0.1 & 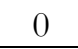 & 0.16 & 0.71 & 0.59 & 0.45 & 0.3 & .14 & 0.05 & 0.19 \\
\hline \multirow{5}{*}{$y=10$} & 0 & & 0.25 & 0.43 & 0.61 & 76 & 0.89 & 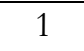 & & 0.27 & 0.48 & 0.67 & 0.84 & 0.98 & 1.1 \\
\hline & 10 & 0.14 & 0.04 & 0.22 & 0.4 & 56 & 0.71 & 0.83 & & 0.05 & 0.25 & & 61 & 0.77 & 0.91 \\
\hline & 20 & & 0.1 & 0 & 0.17 & 0.33 & .48 & 0.61 & & 0.18 & & & 0.36 & 0.52 & 0.67 \\
\hline & 30 & 0.48 & 0.35 & 0.21 & 0.08 & 0.1 & 0.24 & 0.37 & 0.53 & 0.39 & 0.24 & 0.1 & 0.1 & 0.25 & 0.4 \\
\hline & 40 & 0.61 & 0.51 & 0.41 & 0.29 & 0.15 & 0 & 0.07 & 0.69 & 0.59 & 0.47 & 0.34 & 0.2 & 0.06 & 0.11 \\
\hline \multirow{5}{*}{$y=15$} & 0 & & 0.28 & 0.47 & 0.64 & & & & & & & & 0.88 & 1.02 & 1.14 \\
\hline & 10 & 0.11 & 0.07 & 0.25 & 0.42 & 8 & 0.72 & 0.84 & 0.13 & 0.08 & 0.27 & 0.46 & 0.63 & 0.79 & 0.92 \\
\hline & 20 & & 0.13 & 0 & 0.17 & & .47 & 0.59 & 0. & 0.17 & 0.06 & 0.2 & 36 & 0.51 & 0.65 \\
\hline & 30 & & 0.34 & 0.21 & & & & 0.33 & & & & & & 0.2 & 0.35 \\
\hline & 40 & 0 & 0.5 & 0.42 & 0.31 & & 3 & 0 & 6 & 0. & 0 & 6 & 23 & 0.09 & 0 \\
\hline & & & & $x=$ & 42.3 & & & & & & - & 1.5 & & & \\
\hline & $a$ & 0 & 10 & 20 & 30 & 40 & 50 & 60 & 0 & 10 & 20 & 30 & 40 & 50 & 60 \\
\hline \multirow{5}{*}{$y=0$} & 0 & 0 & & & & & & & & & & & & & \\
\hline & 10 & 0.24 & 0.02 & 0.22 & 0.77 & & & 1 & 0 & 0.01 & & & 68 & 39 & 1.06 \\
\hline & 20 & 0.46 & 0.25 & 0.05 & & & & 0. & & & & & 41 & 0.63 & 0.83 \\
\hline & 30 & & 0.48 & 0.28 & & & & 0. & & 0.57 & & & 3 & & 0.56 \\
\hline & 40 & 0.83 & 0.68 & 0.51 & 0.32 & 4 & .12 & 0.2 & 0.96 & 0.8 & & & 19 & 0.08 & 0.28 \\
\hline \multirow{5}{*}{$y=5$} & 0 & 0.03 & 0.26 & 0.48 & 0.69 & 0.88 & 1.04 & 1.17 & 0.03 & 0.28 & 0.52 & 0.74 & 0.95 & 1.12 & 1.26 \\
\hline & 10 & & 0.02 & 0.24 & 0.45 & 0.65 & & 0.99 & 0.24 & 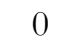 & 0.23 & & 68 & 0.88 & 1.05 \\
\hline & 20 & 0.43 & 0.23 & 0.05 & 0.19 & 0.39 & 0.58 & 0. & & 0.28 & & & 0.38 & 0.59 & 0.78 \\
\hline & 30 & 0.64 & 0.47 & 0.3 & 0.13 & 0.14 & 0.31 & 0.49 & 0.74 & 0.56 & 0.36 & 0. & 0.1 & 0.29 & 0.49 \\
\hline & 40 & 0 & 0.68 & 0.53 & 0.37 & & 0.09 & 0.2 & 0.94 & & & & 0.26 & 0.08 & 0.18 \\
\hline \multirow{5}{*}{$y=10$} & 0 & & 0.29 & 0.52 & 0.73 & 0.91 & 1.07 & 1.2 & 0.06 & 0.32 & 0 . & & 0.99 & 1.16 & 1.29 \\
\hline & 10 & 0.16 & 0.05 & 0.26 & 0.47 & 0.66 & 0.83 & 0.98 & 0.21 & 0 & 0.26 & 0.48 & 0.7 & 0.89 & 1.05 \\
\hline & 20 & & 0.22 & 0.05 & 0.19 & 0.38 & 0.56 & 0.72 & 0.47 & 0.26 & 0.02 & 0.16 & 0.37 & 0.57 & 0.75 \\
\hline & 30 & & 0.46 & & 0.15 & & 0.27 & 0.43 & 0.71 & 0.54 & 0.36 & & 0.08 & 0.24 & 0.43 \\
\hline & 40 & 0.71 & 0.68 & 0.55 & 0.41 & 0.26 & 0.13 & 0.15 & 0.91 & 0.79 & 0.65 & 0.49 & 0.31 & 0.14 & 0.11 \\
\hline \multirow{5}{*}{$y=15$} & 0 & & 0.34 & 0.56 & 0.78 & 0.96 & 1.12 & 1.25 & 0.1 & 0.36 & 0.61 & 0.84 & 1.05 & 1.22 & 1.35 \\
\hline & 10 & 0.14 & 0.08 & 0.29 & & 0.69 & 0.86 & 1 & 0.17 & 0.06 & 0.3 & & 0.73 & 0.92 & 1.08 \\
\hline & 20 & 0.37 & 0.19 & 0.05 & & 0.38 & 0.55 & 0.71 & 0.43 & 0.23 & 0 & 0.17 & 0.38 & 0.57 & 0.75 \\
\hline & 30 & & 0.45 & 0.3 & 0.17 & 0.13 & 0.25 & 0.39 & 0.68 & 0.52 & 0.36 & & 0.08 & 0.22 & 0.39 \\
\hline & 40 & 0.76 & 0.67 & 0.56 & 0.44 & 0.3 & 0.18 & 0.12 & 0.88 & 0.78 & 0.66 & 0.51 & 0.35 & 0.19 & 0.09 \\
\hline
\end{tabular}




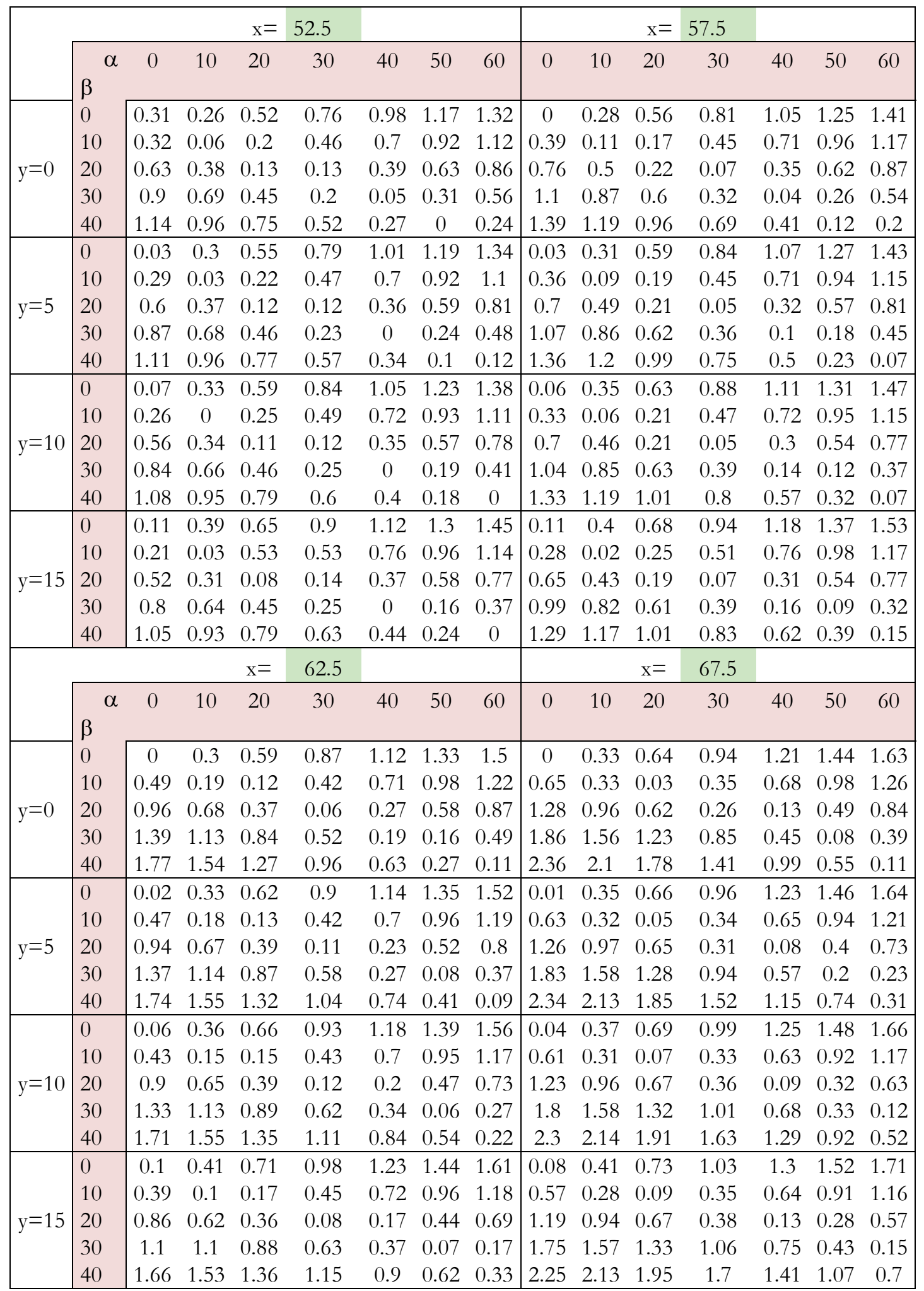

Table B2: Numerical values obtained for $Y_{\text {II }}$. 